Esta revista forma parte del acervo de la Biblioteca Jurídica Virtual del Instituto de Investigaciones Jurídicas de la UNAM

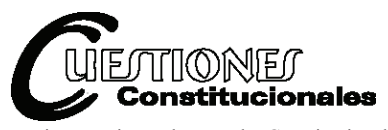

Revista Mexicana de Derecho Constitucional

Núm. 36, enero-junio 2017

\title{
LA CONSTITUCIÓN DE QUERÉTARO. REVOLUCIÓN Y CONSTITUCIÓN, ASPECTOS ORIGINALES Y SUGESTIVOS DESDE EL DERECHO CONSTITUCIONAL COMPARADO*
}

\author{
THE CONSTITUTION OF QUERÉTARO. REVOLUTION \\ AND CONSTITUTION, ORIGINAL AND STIMULATING ASPECTS \\ FROM THE COMPARATIVE CONSTITUTIONAL LAW
}

\section{Antoni ABAT I NINET**}

RESUMEN: El presente artículo analiza las relaciones entre los conceptos de Constitución y revolución, poniendo especial énfasis en el caso particular mexicano. Para ello, se introduce cierto análisis histórico con el fin de contextualizar la Constitución y el rol de punto final y punto de partida que ésta ha jugado en el proceso revolucionario mexicano. El análisis continúa con los elementos revolucionarios que incorporó y consolidó el texto constitucional de 1917, en especial el constitucionalismo social-laboral, la recuperación de la soberanía nacional y el laicismo republicano mexicano. Otro punto es el estudio, desde la perspectiva y metodología del derecho constitucional comparado, de elementos constitucionales mexicanos que no han tenido la atención por su carácter innovador y su ahondamiento en los principios democráticos. Finalmente, se concluye con la revisión de algunos aspectos analizados y se invita al pueblo mexicano a seguir dibujando el idilio entre su Constitución y su revolución.

Palabras clave: Constitución, teoría de la revolución, constitucionalización de elementos revolucionarios, constitucionalismo social, soberanía nacional, relación Estado e Iglesia.
ABSTRACT: This article analyzes the relationship between the concepts of constitution and revolution with special emphasis to the Mexican particular case. For this, some historical analysis is introduced to contextualize the constitution and the role of ending point and starting point that has played in the Mexican revolutionary process. The analysis continues with of the revolutionary elements incorporated or consolidated by the Constitution of 1917, particularly the sociallabor constitutionalism, the recovery of national sovereignty and the Mexican republican laicism. Another point consists in the analysis from the perspective and methodology of comparative constitutional law of some Mexican constitutional element that have not had the attention they seem to merit for its innovative character and deepening of democratic principles. The article ends with where some of the issues discussed previously and with an invitation to the Mexican people to continue drawing the idyll between its Constitution and its revolution.

Descriptors: Constitution, Theory of Revolution, Constitutionalization of Revolutionary Elements, Social Constitutionalism, National Sovereignty, relationship State and Church.

* Artículo enviado por la Revista Catalana de Derecho Público como parte de las celebraciones por los 100 años de la Constitución.

** Profesor de Derecho constitucional en la Facultad de Derecho de la Universidad de Copenhague, Dinamarca. antoni.abat.ninet@jur.ku.dk. 
Esta revista forma parte del acervo de la Biblioteca Jurídica Virtual del Instituto de Investigaciones Jurídicas de la UNAM

En la nación mexicana, desde la proclamación de la independencia hasta el momento actual, no ha tenido lugar un acontecimiento de tanta magnitud, por la alta idealidad de su intención, por la asombrosa fecundidad de sus principios y por la universal trascendencia de sus resultados, cuanto lo ha sido la promulgación de la Constitución federal de 5 de febrero de $1917 .{ }^{1}$

SUMARIO: I. Introducción. II. Constitución y revolución, el caso de México. III. Aspectos revolucionarios de la Constitución de 1917. IV. Aspectos originales y sugestivos del constitucionalismo mexicano desde la perspectiva del derecho comparado. V. Conclusión. VI. Bibliografía.

\section{INTRODUCCIÓN}

El centenario de la Constitución de 1917 es una excelente ocasión para revisar dos conceptos que son y han sido objeto de análisis tanto en derecho constitucional como en ciencias políticas: las revoluciones y las Constituciones. A este cometido se dedica el primer segmento del artículo. Aunque sea alternando el orden, primero cabría preguntarse si la Constitución de 1917 es realmente tal en un sentido moderno del término. Obviamente, la Constitución de Querétaro, en el sentido clásico del término politeia o, más genérico, el de norma fundamental de la comunidad política, es una Constitución. Pero si la sometemos al escrutinio que establece el artículo 16 de la Declaración del Hombre y del Ciudadano de París de 1789 - según el cual una sociedad en la que la garantía de los derechos no está asegurada, ni la separación de poderes determinada, no tiene Constitución-, podría generar más dudas.

Un análisis textual del documento constitucional no deja dudas en cuanto a la protección de las garantías, que pasará a ser un elemento de identidad

1 Molina Enríquez, Andrés, Los grandes problemas nacionales, México, ERA, 1909, p. 470. 
Esta revista forma parte del acervo de la Biblioteca Jurídica Virtual del Instituto de Investigaciones Jurídicas de la UNAM

constitucional mexicano; ni tampoco en cuanto a la separación de poderes, respecto a la cual, aunque el sistema político sea un presidencialismo casi omnipotente, el título tercero plasma literalmente dicha separación. Sin embargo, si analizamos la aplicación real de dichos principios, se generarían más dudas. Se podría incluso llegar a afirmar que hasta el año 2000, con la conclusión del presidencialismo, ${ }^{2}$ se ha producido un mayor ahondamiento en la separación de poderes, México tenía una Constitución, pero carecía de constitucionalismo, en un sentido moderno del término. En cualquier caso y si bien los requerimientos de la declaración francesa son pocos, con la alternancia en el poder puede llegar a afirmarse que este factor finalmente se corrigió.

En relación con la revolución, tampoco es sencilla su conceptualización o, como mínimo, también se han generado dudas sobre si ésta fue tal. Es de sobra conocido que bajo la rúbrica de "Revolución mexicana" se incluyen múltiples movimientos políticos, ideológicos y sociales, revueltas e incluso movimientos contrarrevolucionarios y guerras civiles que envolvieron el acontecimiento político más importante del pasado siglo pasado en México. Esta heterogeneidad ha puesto en jaque, desde un punto de vista teórico, la propia existencia de la revolución, del número de revoluciones, o la falta de un carácter nacional mexicano de las revueltas. Como afirma Martínez Hoyos, no podemos hablar de un único proceso, sino de muchos, dentro de una dinámica de extrema complejidad. ${ }^{3}$

No es objeto de este artículo analizar, desde un punto de vista crítico, estos elementos, pero sí destacar algunos leitmotivs aparejados al momento fundacional que supuso la revolución y su posterior acomodamiento constitucional en 1917. En concreto, los valores de nacionalismo, la identidad propia frente a los extranjeros y la conciencia colectiva, la reforma agraria, el indigenismo y la protección laboral, a la par de una democratización y separación de poderes especialmente en las épocas de Madero y Carranza, se plasmaron en el texto constitucional.

Después de la presente introducción, la segunda sección analiza la relación Constitución-revolución desde un plano teórico, poniendo especial

2 "Presidencialismo" o la predominación de forma ininterrumpida en el Poder Ejecutivo de un solo partido político, el Partido Revolucionario Institucional (PRI). Zamora, Stephen y Cossío, José Ramón, "Mexican constitutionalism after presidencialismo", International Journal of Constitutional Law I-CON, vol. 4, núm. 2, 2006, pp. 411-437.

3 Martínez Hoyos, Francisco, Breve historia de la Revolución mexicana, Madrid, Nowtilus, 2015, p. 12. 
Esta revista forma parte del acervo de la Biblioteca Jurídica Virtual del Instituto de Investigaciones Jurídicas de la UNAM

atención en el caso mexicano y su casuística concreta, por sus particularidades históricas y por las diversas interpretaciones sobre el rol que ha desarrollado la Constitución de Querétaro en el proceso revolucionario. En esta sección se analiza la relación de continuidad/ruptura que tuvo la Constitución de 1917 con su predecesora de 1857. Como podremos apreciar posteriormente, la necesidad de ruptura es clave, desde el punto de vista teórico, para poder considerar un texto constitucional como la culminación de un proceso revolucionario.

La tercera sección se dedica al análisis de los elementos revolucionarios que, bien ex novo o bien ahondando los iniciados en la Constitución de 1857, establece el texto de Querétaro. La sección destaca el "constitucionalismo social", que incluye principios y derechos de carácter social, y los avances en derechos laborales; sigue con la nacionalización de los recursos naturales; y finaliza con la consolidación de la separación definitiva entre el Estado y la Iglesia. El análisis no es meramente textual, sino que también, aunque en menor medida, se reseñan posteriores reformas que han afectado al articulado de los principios o al espíritu revolucionario que impregnaba la redacción original. La intención es tanto visualizar la evolución de los contenidos revolucionarios en el texto como comprobar si la revolución se mantuvo, aunque fuese en el texto constitucional.

En la cuarta sección, el artículo destaca algunos de los elementos de derecho constitucional comparado que el constitucionalismo mexicano ha exportado. Entre estos aspectos destacan elementos claros, como son el constitucionalismo social, la nacionalización de los recursos naturales o el presidencialismo, pero también se analizan cuestiones que parecerían haber merecido más atención en fueros internacionales, como el federalismo mexicano a partir del fin del presidencialismo. Otros aspectos que se destacan es el rol del ejército en la aprobación del texto constitucional en 1917 y sus atribuciones y límites en situaciones de emergencia o excepción, como lo han sido la lucha contra el movimiento zapatista o la lucha contra el narcotráfico.

La última sección se destina a la conclusión, donde se presentan ciertas reflexiones en torno a la necesidad o no de abrir un proceso constituyente y aprobar una nueva Constitución para afrontar los retos que presenta el siglo XXI. 
Esta revista forma parte del acervo de la Biblioteca Jurídica Virtual del Instituto de Investigaciones Jurídicas de la UNAM

\section{CONSTITUCiÓN Y REVOLUCiÓN, EL CASO DE MÉXICO}

\section{La Revolución mexicana en un marco de análisis general}

El centenario de la Constitución de Querétaro, entre otros aspectos, nos invita a reflexionar sobre dos nociones que los académicos del derecho constitucional y de la ciencia política han analizado regularmente, el concepto de revolución y el de constitucionalismo. La relación que algunos autores ya destacaban en el constitucionalismo antiguo (Kagan, Everson o Herman Hansen, entre otros), se acentúa tras las primeras experiencias constitucionales modernas, y en la vivida en Francia y los Estados Unidos de América.

En este sentido, parece interesante situar la experiencia revolucionaria mexicana en un marco teórico de las revoluciones que nos permita entender los acontecimientos que cíclicamente se reproducen a lo largo de la historia moderna en tiempos y localizaciones geográficas diversas. En este análisis de las revoluciones, la acontecida en México a principios del siglo XX debería ocupar un lugar especial, por su casuística particularísima y por cuestiones prácticas y teóricas que un siglo después aún se plantean. La mexicana es o fue una revolución sin grandes figuras de liderazgo de origen burgués, México no se jacta de un Marx o un Engels para proveer ideología progresista; no encontramos un personaje como Ho Chi Minh, Mao, Fidel Castro o Lenin, sino un estallido de realidad, como dirá Octavio Paz. ${ }^{4}$ No obstante, cabe destacar que la figura de Emiliano Zapata o la de Pancho Villa han transcendido globalmente y siguen utilizándose como modelos políticos revolucionarios décadas después.

Esta carencia del fenómeno revolucionario mexicano, la cual se ha destacado en ocasiones desde un punto de vista peyorativo o de descrédito, entiendo que puede interpretarse contrariamente. La revolución fue ante todo un fenómeno popular, y las élites culturales, económicas, políticas o sociales, si bien jugaron un papel esencial, no monopolizaron ni teórica ni prácticamente la revolución en México. La alta tasa de analfabetismo, superior al 77\%, y el carácter mayoritariamente agrícola de la sociedad mexicana de principios del siglo pasado no fueron óbice para afirmar, como hace Martínez Hoyos, que la Revolución mexicana, como la francesa, empezó

4 Ibidem, p. 21; Cline, Howard F., "México: versión madura de una revolución latinoamericana”, en Stanley R., Ross (ed.), ¿Ha muerto la Revolución mexicana?, México, La Red de Jonás, 1972, p. 89. 
Esta revista forma parte del acervo de la Biblioteca Jurídica Virtual del Instituto de Investigaciones Jurídicas de la UNAM

con una revuelta de notables encabezada por Francisco Madero, quien a la postre llegó a ser presidente de la República.

La carencia de un líder ideológico claro ha facilitado la reinterpretación del discurso "revolucionario" por parte del partido oficial (PRI), convirtiendo la Revolución mexicana en algo ecléctico, elástico y pragmático. ${ }^{5}$ Este hecho también se puede vincular con el uso y abuso del término revolucionario en México con el fin de generar una aura de legitimación y épica a los sucesivos gobiernos. Elasticidad del concepto que también ha generado discordia sobre cuándo finalizó la Revolución mexicana, si es que ésta jamás finalizó. Entre los "sepultureros", tampoco hay acuerdo sobre cuándo la Revolución finó; así, hay quienes abogan que la Revolución acabó con la aprobación de la Constitución, quienes sitúan su final coincidiendo con el final de la Segunda Guerra Mundial (Silva Herzog), quienes consideran que el continuo cuadro de violaciones a la Constitución frustraba las conquistas de la revolución (Colín) y, finalmente, hay quien considera que fue la Constitución y la consiguiente dictadura que sufrió el país (Cosío Villegas) quienes mataron el espíritu revolucionario. ${ }^{6}$

También hay algunos historiadores (Schettino) que han negado que los hechos comprendidos en México desde la caída de Porfirio hasta la aprobación de la Constitución en 1917 sean hechos objetivos constitutivos de una revolución, o quienes consideran que la Revolución persiste y pervive un siglo después en México. No cabe duda del carácter revolucionario de dichos acontecimientos, incluso si estos hechos se analizan desde la perspectiva expuesta por la obra de Hannah Arendt, On revolution, no se puede llegar a otra conclusión. Si bien Arendt omite las referencias a la Revolución mexicana y su conceptualización parte del análisis detallado de la Revolución francesa, en menor medida de la Revolución americana, con ciertas alusiones a la Revolución rusa y pocas referencias a las revoluciones china y húngara, puede llegar a afirmarse que la mexicana es una revolución en sentido arendtiano.

De las diferentes características que destaca Arendt, como el carácter intrínseco que la violencia desarrolla en el concepto de revolución, en México la violencia se produjo y en muchas ocasiones de forma aleatoria, gratuita y desmesurada. Son famosos algunos episodios de violencia implementada por algunos personajes esenciales en la Revolución. En este sentido, a la

5 Cline, Howard F., idem.

6 Stanley R., Ross (ed.), ¿Ha muerto..., cit. 
Esta revista forma parte del acervo de la Biblioteca Jurídica Virtual del Instituto de Investigaciones Jurídicas de la UNAM

violencia inherente a los procesos revolucionarios cabe sumarle, en el caso mexicano, el rol casi monopolizador desarrollado por los caudillos y los militares, como ya destacó Blasco Ibáñez, que aumentaba per se la dosis de violencia consustancial al proceso revolucionario. ${ }^{7}$

El concepto de revolución que Arendt describe está centrado en el establecimiento de las condiciones de libertad como elemento clave y, en especial, en la cuestión social entendida como la distribución de la riqueza en la sociedad. ${ }^{8}$ Claramente, el talón de Aquiles de la oligarquía autoritaria de Porfirio aparece como un elemento esencial en las demandas revolucionarias desde su caída hasta 1917 y que posteriormente pretende solucionar el artículo 27 de la Constitución de Querétaro.

Durante el Porfiriato, el país experimenta un impresionante desarrollo económico, una notable estabilidad política; México comienza a dotarse de una estructura moderna de Estado y deviene una verdadera sociedad nacional orgánica, ${ }^{9}$ si bien el precio es una extrema desigualdad económica y social que convierten el régimen en una oligarquía reaccionaria insostenible. Desigualdades que los porfiristas llegaron a considerar producto de la naturaleza y de la historia, donde unos hombres eran "superiores" y otros "inferiores" y, por tanto, debían estar sometidos.

El mismo Porfirio afirmaba que los hombres no eran iguales sino simplemente semejantes, habiendo unos con más capacidad de mando que otros, siendo éstos quienes deberían mandar: "Así sucedía en las hordas salvajes" y así "pasa también... en los grupos civilizados de una sociedad civilizada y pulcra", donde las "personas más capaces... se impondrán por la fuerza de las cosas y gobernarán a los demás". ${ }^{10}$ Un discurso que bien podría equipararse a la sociedad de castas en la India o a las peores interpretaciones políticas de La República de Platón.

Cuando Arendt se refería a la cuestión social, tenía en mente a aquellos que sufrían por la carencia de los bienes materiales más básicos como consecuencia de una sociedad de cleptócratas. ${ }^{11}$ Bien podía referirse a las élites

7 Blasco Ibáñez, Vicente, El militarismo mejicano, Valencia, Prometeo, 2006.

8 Arendt, Hannah, On Revolution, Nueva York, Penguin Group, 2006, p. 5.

9 Molina Enríquez, Andrés, Los grandes..., cit., pp. 11-14.

10 Parra, Porfirio, "Estudio histórico-sociológico de la Reforma de México", La Gaceta de Guadalajara, Guadalajara, 1906, pp. 81 y 82, disponible en: http://cdigital.dgb. uanl.mx/la/1020002862/1020002862.PDF (consultada el 19 de septiembre de 2016).

11 Arendt, Hannah, On..., cit., p. 8. 
Esta revista forma parte del acervo de la Biblioteca Jurídica Virtual del Instituto de Investigaciones Jurídicas de la UNAM

porfiristas, quienes monopolizaban los ingresos y beneficios económicos a costa de toda la sociedad.

La definición más próxima del termino revolución en la obra de Arendt aparece cuando afirma:

podremos hablar de revolución, únicamente cuando los cambios ocurren en sentido de un nuevo principio, donde la violencia es utilizada para constituir una forma de gobierno diferente que conlleve la formación de un nuevo cuerpo político y donde la liberación de la opresión aspire cuanto menos a la constitución de la libertad. ${ }^{12}$

Anteriormente también había escrito que para la concepción moderna de revolución es crucial que las ideas de libertad y nuevo principio coincidan. ${ }^{13}$ La revolución, por consiguiente, requiere novedad, y que la situación prerrevolucionaria que sufría el pueblo oprimido pueda superarse exclusivamente mediante violencia revolucionaria. La violencia motiva el nuevo principio demostrando a los mismos participantes su nueva capacidad de actuar políticamente.

Algunos de los episodios revolucionarios conllevan ese nuevo principio como nación que se transforma a sí misma. En otras palabras, lo que se viene a significar es que el pueblo no es que necesite transformarse a sí mismo, sino liberarse de la opresión. En México puede llegar a afirmarse que la Revolución significó un nuevo acto fundacional que transformó para siempre la conciencia nacional del pueblo mexicano, y que después la Constitución plasmó tanto política como socialmente.

Incluso antes de Arendt, Hans Kelsen definía la relación entre revolución y constitucionalismo: "una revolución ocurre cuando el orden legal de una comunidad es anulado y remplazado por un nuevo orden de manera ilegítima, es decir, no prescrita por el primer orden legal". ${ }^{14}$ Lo cierto es que aquí se podrían generar ciertas dudas sobre el carácter revolucionario del constitucionalismo mexicano de 1917. Sobre la identificación legal-legítimo y, sobre todo, el agotamiento de la legitimidad en el proceso jurídico, entiendo que el debate planteado por el positivismo se encuentra en estos momentos

12 Idem.

13 Ibidem, p. 25.

14 Jacobshon, Gary Jeffrey, "Theorizing the Constitutional Revolution", Journal of Law and Courts, 2014, p. 6, citando a Kelsen. 
Esta revista forma parte del acervo de la Biblioteca Jurídica Virtual del Instituto de Investigaciones Jurídicas de la UNAM

superado. Molina tiene razón cuando afirma que el hecho de que la Constitución de 1857 haya determinado con precisión el procedimiento de reforma y que la Constitución de 1917 no haya seguido dicho procedimiento, nada importa para la validez de la misma. ${ }^{15}$ Además, paradójicamente, el no seguir el proceso cualifica la Constitución como revolucionaria en términos kelsenianos, ya que la sustitución de un texto constitucional por otro no se realiza siguiendo las normas prescritas por el primero. ${ }^{16}$

La cuestión que se nos plantea es si la Constitución de 1917 remplazaba a un nuevo orden, como Carranza proponía tres años antes de su aprobación: "Hay que removerlo todo y crear una nueva Constitución cuya acción benéfica sobre las masas nada, ni nadie, pueda evitar". ${ }^{17}$ Los debates constituyentes demuestran las dudas existentes sobre este extremo, titubeos sobre si había que aprobarse una Constitución nueva o reformar el texto vigente desde 1857. En este sentido, esta duda era la mayor distensión entre los doscientos diez diputados carrancistas, que monopolizaban la Asamblea Constituyente como consecuencia de su victoria en los campos de batalla contra villistas, zapatistas y huertistas. ${ }^{18}$

La Constitución de 1917 tiene fuertes similitudes con su predecesora puesto que reproduce sus principios y estructura institucional, además de conceptualizarse como una reforma de la promulgada el 5 de febrero de 1857, hecho que señala cierta línea de continuidad. Sin embargo, ello no fue óbice para que el texto de Querétaro introdujese elementos distintivos fundamentales - en consonancia con la ola progresista de los tiempos en los que se enmarcaba- y constitucionalizase el sustrato ideológico revolucionario, que resume De La Madrid en tres nociones fundamentales: democracia, nacionalismo y justicia social. ${ }^{19}$

En cualquier caso, el elemento de distinción sustancial entre ambos textos constitucionales radica en el espíritu de la Constitución de Querétaro que, si bien no es un principio tangible o circunscrito a uno o más artículos de la Constitución, el autor lo comprende en la superposición de la sociedad

15 Molina Enríquez, Andrés, Los grandes..., cit., p. 471.

16 Jacobshon, Gary Jeffrey, "Theorizing the...," cit., p. 6.

17 Martínez Hoyos, Francisco, Breve historia..., cit., p. 190.

18 Idem.

19 Madrid, Miguel de la, La Constitución de 1917 y sus principios políticos fundamentales, Universidad de Colima, Instituto Universitario de Investigaciones Jurídicas, 2002, disponible en: http://bibliohistorico.juridicas.unam.mx/libros/1/95/4.pdf (consultada el 29 de agosto de 2016). 
Esta revista forma parte del acervo de la Biblioteca Jurídica Virtual del Instituto de Investigaciones Jurídicas de la UNAM

al individuo, ${ }^{20}$ pero que entiendo puede extenderse a otros aspectos básicos, como la concretización en la esfera constitucional de la división entre Estado e Iglesia, el aspecto de reconocimiento de los derechos sociales y laborales.

A modo de conclusión de este apartado destacan los siguientes puntos: a) que la Revolución mexicana incluya diferentes revoluciones y revueltas, no cuente con un líder intelectual destacado y exista cierta duda razonable sobre cuándo ha sido su punto final, no es óbice para considerar los hechos como revolucionarios; 2) aunque la Constitución de 1917 tenga similitudes con su predecesora, incluso en el número de artículos, tampoco la descalifica como Constitución revolucionaria, puesto que, sin seguir el procedimiento de reforma, estableció un nuevo sistema jurídico y un nuevo espíritu constitucional arraigado en el acto revolucionario fundacional $\mathrm{y}$, por último, 3) el hecho de que las revoluciones sean o no mortales no cuestiona la enorme trascendencia que la revolución y su Constitución han jugado en México, tanto que su discurso y valores no se pueden enterrar.

\section{El rol complementario de la Constitución de 1917 en la Revolución mexicana}

Que la Constitución de Querétaro es la Constitución de la revolución no ofrece duda alguna por el momento en el que se aprueba el documento, por los valores y el espíritu que recoge. Además, se trata de un documento aprobado tras la guerra civil entre los revolucionarios que combatieron a Porfirio y depusieron al contrarrevolucionario presidente Huerta.

Las Constituciones y el constitucionalismo son herramientas para implementar racionalidad política y legal; razón legal desde la cúspide de la pirámide del sistema. Nada escapa al proceso de racionalización legal, como nos recuerda Weber, y la revolución no es una excepción. ${ }^{21}$ Hay quien ha entendido que ese proceso de necesaria tipificación y codificación en un texto legal "mata" un proceso per se revolucionario. Como si revolución y razón fuesen elementos incompatibles por naturaleza. Sin embargo, parece difícil pensar que, sin tal proceso, sin la Constitución y su flexibilidad, los valores de la revolución, su épica y espíritu hubiesen podido persistir hasta nuestros días.

20 Molina Enríquez, Andrés, Los grandes..., cit., p. 471. 2011.

21 Weber, Max, Ética protestante y espiritu del protestantismo, México, Colofón, 
Esta revista forma parte del acervo de la Biblioteca Jurídica Virtual del Instituto de Investigaciones Jurídicas de la UNAM

La Constitución de 1917 es la juridificación de los valores revolucionarios y de un nuevo orden político, supone la plasmación en la norma jurídica y política más importante del país del momento fundacional que supuso la revolución. México no sería tal sin su revolución, y la Constitución desarrolla un punto decisivo en el proceso y mantiene vivo el espíritu. No podría ser de manera distinta por el rol supremo que juega la Constitución en el sistema político y legal. La Constitución de 1917 no se limita a ser un documento jurídico con carácter normativo, sino que tiene una transcendencia omnipresente, juridifica la nueva identidad del pueblo mexicano surgida tras el momento revolucionario y consolida el sentido de identidad nacional común. Podría llegar a afirmarse que en México, la revolución sería uno de esos momentum (junto a la independencia); y la Constitución, el punto de partida para que el pueblo mexicano se considerase como tal.

La relación entre revolución y Constitución es simbiótica, sin la Constitución, y su imperio legal, político y epistemológico, no sabemos dónde hubiese quedado la épica revolucionaria y el carácter fundacional de la misma, y sin la revolución, la Constitución probablemente no hubiese pasado de ser un texto sin "alma", no hubiese sido más que una especulación de gabinete..$^{22}$ Tal y como afirma Frank Tannenbaum, la verdadera revolución ha sido la materialización paulatina del mandato constitucional. ${ }^{23}$ Dicho de otra manera, la revolución ha sido la Constitución y su aplicación, cuanto menos en algunos aspectos. Si bien esta afirmación puede parecer correcta, existen obviamente interpretaciones totalmente antagónicas (Espinoza de los Monteros); y, además, según cómo se interprete dicha aseveración, podría minusvalorar el contenido revolucionario que supuso el proceso de acomodación constitucional. A continuación se analiza la articulación constitucional concreta de los principios revolucionarios.

\section{Aspectos REVOluCiOnARIOS DE LA CONSTITUCIÓN DE 1917}

Los aspectos revolucionarios originales en la Constitución de 1917 más relevantes son: el "constitucionalismo social", que abarca los principios y derechos de carácter social y los avances en derechos laborales; la nacio-

22 Echeverría Álvarez, Luis, "Nuestra revolución no ha terminado", en Stanley, R Ross (ed.), ¿Ha muerto..., cit., p. 278.

23 Tannenbaum, Frank, "Algunas reflexiones sobre la revolución mexicana”, en Stanley R., Ross (ed.), ¿Ha muerto..., cit., p. 188. 
Esta revista forma parte del acervo de la Biblioteca Jurídica Virtual del Instituto de Investigaciones Jurídicas de la UNAM

nalización de los recursos naturales y la consolidación de la separación definitiva entre el Estado y la Iglesia.

\section{Constitucionalismo social}

Si existe un elemento que ha generado consenso entre las diferentes generaciones académicas, es considerar el carácter social del constitucionalismo mexicano como un hecho característico del mismo. Puede llegar incluso a afirmarse que el carácter social es el elemento más definitorio de la identidad constitucional mexicana y, sin duda, el que más reconocimiento, repercusión e influencia ha tenido en el constitucionalismo moderno.

Algunos de los derechos sociales (humanos), referidos como garantías individuales en la Constitución de 1917, son en parte herencia del texto constitucional antecesor, ahora bien, la Constitución de Querétaro amplía y desarrolla estos derechos de manera extensa y prolija. Entre estas garantías sociales destacan el primer artículo del texto constitucional, que las universaliza junto a una cláusula de limitación genérica; ${ }^{24}$ y el artículo 2o., que contiene la prohibición de la esclavitud, uno de los pocos derechos humanos absolutos e ilimitables, como también se deduce de la redacción del texto constitucional.

Especial mención debe realizarse al artículo 3o., relativo al derecho a la enseñanza libre, gratuita y laica, que impide a cualquier corporación religiosa establecer o dirigir escuelas de primaria. El derecho a la educación, que tras posteriores reformas debe guiarse por el principio "nacional-democrático", debiendo ser de calidad, luchará contra la ignorancia, el fanatismo, las servidumbres y los prejuicios, fomentando una mejor convivencia junto con el aprecio a la dignidad de la persona y obligando tanto a la Federación como a los estados y a los municipios a proveer de dicha enseñanza en sus diferentes grados (prescolar, primaria y secundaria). En relación con la enseñanza, como posteriormente se detalla en este artículo, se instrumentaliza por parte del estado como caballo de batalla contra la intromisión del clero, a quien se pretende limitar las posibilidades de adoctrinamiento en tempranas edades.

24 Barak, Aharon, Proportionality, Constitutional Rights and Their Limitations, Cambridge, Cambridge University Press, 2012, p. 133. 
Esta revista forma parte del acervo de la Biblioteca Jurídica Virtual del Instituto de Investigaciones Jurídicas de la UNAM

Además, entre las garantías que estipula la Constitución de 1917, también destacan las establecidas en el artículo 7o., en el que aparece la libertad de prensa, declarando inviolable la libertad de escribir y publicar escritos sobre cualquier materia y, consiguientemente, prohibiendo la censura; el artículo 8o., que establece el derecho de petición; el artículo 9o., que establece el derecho de asociación, si bien limita la asociación con fines políticos a los ciudadanos de la República; el artículo 10, sobre el derecho a poseer armas con fines de proteger la seguridad y legítima defensa, así como el domicilio - lo que limita el ámbito objetivo de aplicación de este derecho si se compara con el establecido en la segunda enmienda de los Estados Unidos de América-; el artículo 12, sobre la prohibición de los títulos de nobleza; en los Estados Unidos mexicanos no se otorgan títulos de nobleza, ni prerrogativas y honores hereditarios, ni se reconocen los otorgados por cualquier otro país.

Con independencia del listado de derechos fundamentales sociales precedentes y siguiendo la nomenclatura que utiliza De la Madrid, ${ }^{25}$ en este artículo se divide el contenido social de la Constitución en dos esferas, la establecida en el artículo 27 (de los derechos de los campesinos) y la acomodada básicamente en el artículo 123 (los derechos de los trabajadores).

El extensísimo artículo 27 es, como hemos adelantado, uno de los elementos distintivos por antonomasia del carácter social de la Constitución. Se han escrito y se seguirán escribiendo ríos de tinta sobre este artículo que ha sufrido un total de veinte reformas de diversa intensidad y calado, siendo la última de estas en 2016. El artículo 27 tiene entre sus objetivos primordiales la nacionalización de los recursos naturales, la recuperación de la soberanía nacional en determinados sectores económicos y la ruptura del control de la institución del latifundio y la oligarquía de los grandes terratenientes mexicanos y extranjeros.

La nacionalización y un nuevo concepto de propiedad privada revolucionario se presentan de lleno en el primer párrafo del artículo 27, cuando afirma: "la propiedad de las tierras y aguas comprendidas dentro de los límites del territorio nacional corresponde originariamente a la nación, la cual ha tenido y tiene el derecho de transmitir el dominio de ellas a los particulares, constituyendo la propiedad privada". En la teoría constitucional, la nacionalización se ejecutó de manera brillante por parte del Constituyente, realizando una analogía legal de los precedentes utilizados en el periodo

25 Madrid, Miguel de la, "La Constitución...", cit., pp. 43-48. 
Esta revista forma parte del acervo de la Biblioteca Jurídica Virtual del Instituto de Investigaciones Jurídicas de la UNAM

de la colonización, cuando entonces se separaba el derecho de propiedad de la posesión; y si bien en época del virreinato la propiedad pertenecía al rey de España, con la aprobación de la nueva Constitución, la titularidad pasa a ser estatal. ${ }^{26}$

Los derechos sociales, y en particular el de propiedad, quedan antepuestos al derecho de propiedad del individuo, y se introducen las bases de un sistema económico y un principio social que regirá el país desde entonces. Como afirma Molina, el cambio es fundamental puesto que la jurisprudencia establecida por la Corte Suprema de la Nación, anterior al Plan de San Luis y basándose en el artículo 27 de la Constitución de 1857, consideraba los derechos de dominio de los particulares como de propiedad perfecta y, salvo el caso de expresa limitación, ninguna otra le podían imponer, ni las leyes civiles pretéritas o futuras, ni la misma Constitución con todo su carácter fundamental y con toda su autoridad suprema. ${ }^{27}$

El texto constitucional prevé el aprovechamiento de los elementos naturales susceptibles de apropiación, con objeto de hacer una distribución equitativa de la riqueza pública, cuidar de su conservación, lograr el desarrollo equilibrado del país y el mejoramiento de las condiciones de vida de la población rural y urbana; lo que viene a suponer una política económica intervencionista donde el rol del Estado pasa a ser nuclear, un rol intervencionista que se verá incrementado a partir de la reforma de 1983.

Los elementos naturales susceptibles de apropiación listados en el artículo 27 han ido incrementándose y actualizándose (en ocasiones liberalizándose) por sucesivas reformas que, si bien han afectado el ámbito material y han liberalizado ciertos sectores económicos, puede afirmarse que no han desvirtuado la naturaleza y espíritu revolucionarios.

De entre estas reformas cabría destacar, por ser las de mayor calado, las siguientes: 1) la reforma de 1938, que tuvo como objeto la inclusión del petróleo y de los hidrocarburos sólidos, líquidos o gaseosos sobre los que no se otorgaran concesiones y sobre los que la nación llevó a cabo la exploración y extracción; 2) la reforma de 1960, que, por una parte, afectó a la energía eléctrica con objeto de prestación de servicio público, si bien éste se volvió a reformar en 2013 liberalizando de cierta manera el sector; y, por otra parte, extendió la propiedad de la nación al espacio situado sobre el territorio nacional en la extensión y términos fijados por el derecho in-

27 Ibidem, p. 474. 
Esta revista forma parte del acervo de la Biblioteca Jurídica Virtual del Instituto de Investigaciones Jurídicas de la UNAM

ternacional — posteriormente, en la reforma de 1976 se concretó en la zona económica exclusiva de 200 millas marinas náuticas a partir de la línea de base desde la cual se mide el mar territorial—; 3) la reforma de 1992, que tuvo como efecto principal diversificar los mecanismos de incorporación de suelo de propiedad social al mercado inmobiliario urbano y provocar un auge del mercado libre; con anterioridad a la reforma del artículo 27 constitucional, las tierras ejidales que rodeaban la mayor parte de las ciudades mexicanas sólo podían incorporarse al desarrollo urbano mediante el mercado ilegal de suelo; con el nuevo artículo 27 , por primera vez se permitió la venta del suelo ejidal y comunal. ${ }^{28}$

El extenso artículo 27 ha mantenido su originalidad y con base en las sucesivas reformas puede afirmarse que ha ido cumpliendo con alguno de sus cometidos de manera encomiable; en particular, el de mantener la soberanía nacional sobre los recursos naturales y actividades económicas estratégicas del Estado y el de limitar el poder de las oligarquías latifundistas con las cuales se había identificado el capital extranjero, esencialmente el de los Estados Unidos de América, que había adquirido enormes porciones de tierra.

\section{Derechos sociales de carácter laboral}

El régimen de protección de los derechos de la clase trabajadora, se inicia con la redacción del artículo 4o., que establece la libertad de trabajo. La formulación era especialmente relevante en un país donde esta libertad se ofendía de manera muy generalizada y de diversas maneras, desde remuneraciones ínfimas hasta cobros en vales o a crédito, pasando por jornadas interminables y sin tener en consideración la edad de los trabajadores, sus condiciones de salubridad e higiénicas. Condiciones denigrantes y sórdidas que no acontecían exclusivamente en México a principios del siglo pasado.

El artículo 4o. afirma que a ninguna persona se le podría negar la libertad de elegir la profesión, industria, comercio o trabajo que la acomode, siendo lícitos. El régimen de protección viene ampliamente desarrollado en el artículo 123, que, reformado hasta en veintitrés ocasiones, ha sido

28 Oliveira Lozano, Guillermo, "La reforma al artículo 27 constitucional y la incorporación de las tierras ejidales al mercado legal de suelo urbano en México", Scripta Nova, 2005, disponible en: http://www.ub.edu/geocrit/sn/sn-194-33.htm (consultada el 29 de agosto de 2016). 
Esta revista forma parte del acervo de la Biblioteca Jurídica Virtual del Instituto de Investigaciones Jurídicas de la UNAM

y sigue siendo paladín de los derechos de obreros, jornaleros, empleados domésticos y personas sujetas a un contrato laboral.

El catálogo de derechos y limitaciones que enumera dicho artículo es extensísimo y lo convierte en digno predecesor de muchos de nuestros códigos de trabajo y seguridad social modernos. Entre los aspectos más significativos destacan el límite de la jornada laboral a ocho horas; la exigencia de unas condiciones de salubridad e higiene en el ámbito de trabajo; la adecuación de las jornadas laborales a menores de edad y la prohibición de contratar a los niños menores de doce años; el reconocimiento a las bajas por maternidad y periodo de lactancia; la estipulación de un salario mínimo y no discriminación en cuanto al salario percibido por razones de sexo o nacionalidad; y la necesidad de pagarse el salario en moneda de curso, lo que significaba un avance notable en 1917 en la lucha contra el abuso de los trabajadores.

Otros avances regulados en el redactado del artículo 123 fueron la regulación sobre la responsabilidad en los accidentes laborales; derechos sindicales y asociaciones laborales, así como el reconocimiento al derecho de huelga y parones laborales; se creó un sistema de conciliación y arbitraje para dirimir conflictos o diferencias; indemnización por despido improcedente; preferencias de los créditos en favor de los trabajadores a favor de sus patronos; creación de bolsas de trabajo; se consideraron las cláusulas contractuales abusivas consideradas nulas iuris et de iure; periodos de descanso y vacaciones legales y la creación de la seguridad social.

En definitiva, el artículo 123 impregna y consagra por sí mismo el carácter revolucionario del texto constitucional, una referencia de antaño y en la actualidad que ha posibilitado que una gran parte del pueblo llano, tanto del campo como de la ciudad, se haya organizado con el fin de beneficiarse de hecho con la legislación obrera. ${ }^{29}$ Además, cabe señalar que en el mundo laboral se avanzaba al menos en un plano teórico a una mayor igualdad de género, hecho que no se extendió a los derechos políticos, donde las mujeres continuaron privadas del sufragio, si bien otros países ya habían implementado dicha política de igualdad de género, en especial las Constituciones escandinavas (Suecia y Noruega), o incluso con anterioridad a éstas, Nueva Zelanda y algunos estados de los Estados Unidos de América.

29 Tannenbaum, Frank, "La revolución agraria mexicana", Senderos, Los expedientes secretos, Universidad de México, 2002, p. 91. 
Esta revista forma parte del acervo de la Biblioteca Jurídica Virtual del Instituto de Investigaciones Jurídicas de la UNAM

Otro progreso fue la mejora del recurso de amparo (artículo 107) que destacaba Carranza en su discurso de 19 de diciembre de 1916 del Congreso Constituyente como uno de los pilares básicos a aplicar, ya que, si bien el sistema constitucional mexicano había instaurado este mecanismo de defensa de los derechos fundamentales, el mismo, en opinión del que fuera presidente, "se desnaturalizó hasta convertirse primero en un arma política; y después, en un medio apropiado para acabar con la soberanía de los estados; puesto que quedaron sujetos de la revisión de la Suprema Corte". El artículo también muy extenso recoge los principios básicos del recurso de amparo tanto en jurisdicción civil como penal, establece el ámbito objetivo y subjetivo y cuestiones de índole procesal, incluidos plazos para la detención, consignación ante la autoridad y la competencia material para reclamar el fallo e interposición ante la Corte Suprema.

\section{Recuperación de la soberanía nacional}

Otro de los factores fundamentales que movieron el constitucionalismo revolucionario mexicano fue la recuperación de la soberanía nacional, que llegó a casi límites extremos. Aquí el contexto histórico es nuevamente necesario para entender el contenido nacionalista de la Constitución de 1917, que, como en otros aspectos, ahonda lo establecido por su predecesora. En relación con la contextualización histórica habría que remontarse a los efectos traumáticos que en el subconsciente nacional mexicano causaron los efectos territoriales del Tratado de Guadalupe Hidalgo de 2 de febrero de 1848, las continuas disputas bélicas territoriales y las intervenciones francesas en México. Todo ello es el precedente sociológico de lo que Carbonell define como xenofobia constitucionalizada. ${ }^{30}$

Entre las disposiciones constitucionales que limitan los derechos de los extranjeros en México destacan la limitación al derecho de propiedad establecida en el artículo 27, reformado en 1960, que establece entre otros aspectos:

30 Carbonell, Miguel, "La xenofobia constitucionalizada", Biblioteca Jurídica Virtual del Instituto de Investigaciones Jurídicas de la UNAM, disponible en: http://historico. juridicas.unam.mx/publica/librev/rev/facdermx/cont/246/art/art10.pdf (consultada el 15 de septiembre de 2016). 
Esta revista forma parte del acervo de la Biblioteca Jurídica Virtual del Instituto de Investigaciones Jurídicas de la UNAM

La capacidad para adquirir el dominio de las tierras y aguas de la Nación, se regirá por las siguientes prescripciones: Sólo los mexicanos por nacimiento o por naturalización y las sociedades mexicanas tienen derecho para adquirir el dominio de las tierras, aguas y sus accesiones o para obtener concesiones de explotación de minas o aguas... En una franja de cien kilómetros a lo largo de las fronteras y de cincuenta en las playas, por ningún motivo podrán los extranjeros adquirir el dominio directo sobre tierras y aguas.

Ciertamente, una lectura plana del texto parecería contradecir la jurisprudencia de la Corte Interamericana de Derechos Humanos en cuanto a la no discriminación por origen nacional.

Otro artículo que diferencia entre mexicanos y extranjeros de manera distinta es el artículo 32, estableciendo el criterio de ius soli para el ejercicio de los cargos y funciones que la Constitución requiera ser mexicano. Se limita, además, el acceso a quienes habiendo nacido en México adquieran otra nacionalidad. El artículo continúa prohibiendo a extranjeros la posibilidad de servir en las fuerzas armadas, policía o seguridad pública en tiempos de paz. Esta "discriminación" de la que habla Carbonell es, sin embargo, práctica habitual en la mayoría de los Estados. Es norma común reservar ciertos cargos a los nacionales como consecuencia de las funciones que se desempeñan o porque puedan implicar secretos de Estado, seguridad nacional $\mathrm{u}$ otros aspectos.

En el caso español, por ejemplo, el Estatuto Básico del Empleado Público, Real Decreto Legislativo 5/2015 de 30 de octubre, explicita, en su artículo 57, que los nacionales de los Estados miembros de la Unión Europea podrán acceder, como personal funcionario, en igualdad de condiciones que los españoles a los empleos públicos, con excepción de aquellos que directa o indirectamente impliquen una participación en el ejercicio del poder público o en las funciones que tienen por objeto la salvaguardia de los intereses del Estado o de las administraciones públicas. La interpretación y laxitud de la última frase del Estatuto se hace depender del contexto histórico político concreto. Otro ejemplo entre muchos otros es el requerimiento de ser nacionales a jueces y magistrados de las cortes supremas y constitucionales que se establecen en la mayoría de las legislaciones, que en ningún caso se considera discriminatorio, si bien una interpretación literal de la mayoría de los artículos de no discriminación e igualdad de dichas Constituciones podría dar a entender lo contrario. 
Esta revista forma parte del acervo de la Biblioteca Jurídica Virtual del Instituto de Investigaciones Jurídicas de la UNAM

El artículo primero de la Constitución que actualmente abre el capítulo de los derechos humanos y sus garantías fue reformado en diferentes ocasiones desde su redacción original que se refería a las garantías, tras las reformas de 2006 y 2011. El párrafo tercero de dicho artículo prohíbe, entre otras, toda discriminación motivada por origen étnico o nacional que tenga por objeto la anulación o menoscabo de los derechos y libertades de las personas. La reforma pasó, pues, por incluir una cláusula de no discriminación por razón de su "origen nacional". Hay quien ha interpretado que tras la inclusión de esta cláusula, las limitaciones a los extranjeros son inconstitucionales, es decir, son unconstitutional constitutional law. ${ }^{31}$ Sin embargo, y siguiendo con la teoría del profesor de Israel, entiendo que la Corte Suprema bien podría aplicar el principio de proporcionalidad sobre este artículo para entender que las limitaciones, una vez pasen los elementos del test de proporcionalidad, son pertinentes.

El derecho de "no discriminación" no es un derecho absoluto, la Corte primero debería valorar si las limitaciones que establecen los artículos 27 , 32 y 33 persiguen un propósito apropiado (como lo parecen ser la defensa de la soberanía nacional y la salvaguarda de los intereses del Estado). El siguiente elemento es la conexión racional, requisito que implica que las medidas utilizadas por la ley limitadora (en nuestro caso la Constitución) pueden realizar o avanzar en el objetivo establecido por la ley, es decir, proteger los intereses del Estado. El siguiente requerimiento que establece el test de proporcionalidad es el de la necesidad. El legislador deberá elegir, de entre todas las medidas que dispone, la que menos limite el derecho humano en cuestión; ¿pueden salvaguardarse los bienes jurídicos (defensa, soberanía nacional y la salvaguarda de los intereses del Estado) mediante una medida menos lesiva en México? La respuesta tal vez haya variado en el siglo de vida de la Constitución; además, la carga de la prueba recae en el legislador. El último elemento a considerar es la proporcionalidad en stricto sensu, es decir, que los beneficios con la limitación de los derechos a los extranjeros sean proporcionales a la limitación del derecho.

La reforma de los artículos 27, 32 y 33 puede haber adecuado la limitación del derecho de no discriminación al test expuesto; $\mathrm{y}$, por consiguiente, la restricción podría interpretarse como amparada en el principio de

31 Jacobshon, Gary Jeffrey, “An Unconstitutional Constitution”, International Constitutional Law Journal, ICON, vol. 4, núm. 3, 2006, pp. 460-487; Barak, Aharon, "Unconstitutional Constitutional Amendments", Israel Law Review, 44, 2011, pp. 321-342. 
Esta revista forma parte del acervo de la Biblioteca Jurídica Virtual del Instituto de Investigaciones Jurídicas de la UNAM

proporcionalidad y no contraria a lo establecido en el artículo primero de la Constitución mexicana y los tratados de derechos humanos ratificados por México.

\section{División Estado-Iglesia}

Otro elemento a destacar de la Constitución de 1917 es la culminación del proceso de separación entre la Iglesia y el Estado. La Constitución de Querétaro continúa el proceso ya iniciado por la conocida Ley Lerdo de 1856 de desamortización de bienes en manos muertas, la Ley Juárez, los artículos 13 y 27 de la Constitución de 1857 y las famosas Leyes de Refor$m a$ incorporadas posteriormente al texto constitucional mediante la reforma propuesta por el presidente Sebastián Lerdo de Tejada.

La ley de desamortización que tiene, tanto en el espíritu como en el redactado y el resultado, similitudes con la ley de desamortización española de Mendizábal aprobada 20 años antes, busca la expropiación forzosa, entre otros, de los bienes que la Iglesia católica había acumulado como beneficiaria de donaciones, testamentos y ab intestatos. Sin embargo, el proceso republicano mexicano fue más ambicioso en el proyecto de separación entre Iglesia y Estado que el español, también debido al contexto histórico y al rol político (reaccionario) que la Iglesia católica había jugado en el país. Episodios como la oposición de la Iglesia al presidente Benito Juárez, incluso situándose a favor de la intervención francesa en el país, o la insurrección armada de los "religioneros" hasta los días de Porfirio Díaz son algunos ejemplos de la tensión existente entre Iglesia y Estado.

La Constitución de Querétaro venía a profundizar dicha separación; así, en el artículo 5o., el texto original establecía la prohibición del establecimiento de órdenes monásticas; el artículo 27 también prohibía a las asociaciones religiosas capacidad para adquirir, poseer o administrar bienes raíces ni capitales impuestos sobre ellos. El mismo artículo completaba la expropiación forzosa sobre templos destinados al culto, obispados, seminarios, colegios de asociaciones religiosas, casas curales o asilos que pasaban a ser propiedad de la nación. Además, se desproveía a la Iglesia de la facultad de intervenir en la enseñanza primaria, investigación científica y la beneficencia, tal y como se ha mencionado previamente.

Finalmente, el artículo 130 del texto constitucional negaba personalidad alguna a las asociaciones que se denominaban iglesias, a los ministros del 
Esta revista forma parte del acervo de la Biblioteca Jurídica Virtual del Instituto de Investigaciones Jurídicas de la UNAM

culto se les limitaba el derecho de reunión pública o privada constituida en forma de junta, ni actos de culto ni de propaganda religiosa, además de limitar la libertad de expresión de los sacerdotes. Tal y como afirma Gerson, negando la identidad jurídica de la Iglesia, la nueva Constitución salvaba el problema de la relación Iglesia-Estado y limitaba la acción eclesial a los confines de la religión exclusivamente. ${ }^{32}$

En definitiva, un artículo producto de su contexto histórico y que impregna de laicismo (artículo 40 de la Constitución) más que de un carácter aconfesional la Revolución mexicana, en un país donde la Iglesia católica sigue teniendo una enorme transcendencia identitaria, cultural, ética y moral. ${ }^{33}$ Con el paso del tiempo, algunas de estas limitaciones fueron reformándose en pro de la defensa de las libertades públicas de todos los ciudadanos mexicanos, también los religiosos, si bien la cláusula limitativa de la libertad de expresión sigue vigente en la Constitución.

En relación con el espíritu que impregna el constitucionalismo revolucionario mexicano y encarnado en su texto de 1917, también pueden destacarse algunos aspectos relacionados con las estrategias y alianzas políticas internacionales. Así, no es casual que México fuera un ardiente defensor de Etiopía contra Mussolini, de la República Española contra la sublevación militar fascista, o un aliado de los Estados Unidos en contra de Hitler y el imperialismo japones.

\section{ASPECTOS ORIGINALES Y SUGESTIVOS DEL CONSTITUCIONALISMO MEXICANO DESDE LA PERSPECTIVA DEL DERECHO COMPARADO}

Desde la perspectiva del derecho constitucional comparado hay una serie de elementos introducidos por el texto constitucional de Querétaro que han sido recurrentes a la hora de establecer análisis y comparaciones. Algunos

32 Gerson, Pedro, "Consolidating the Mexican State: Constitutionalism during the Presidency of Plutarco Elías Calles”, University of Pennsylvania, Scholary Commons, disponible en: http://repository.upenn.edu/cgi/viewcontent.cgi? article $=1009 \&$ context $=$ hist_ honors (consultada el 25 de agosto de 2016).

33 Como ejemplo de esta influencia, cada año millones de personas visitan la Basílica de la Virgen de Guadalupe. El año 2015 según datos de la Presidencia de México llegaron a visitarla 20 millones de personas, más de 5 millones el día 12 de diciembre como motivo de la festividad. Disponible en: http://eleconomista.com.mx/sociedad/2015/12/12/ mas-5-millones-visitan-virgen-guadalupe (consultada el 25 de agosto de 2016). 
Esta revista forma parte del acervo de la Biblioteca Jurídica Virtual del Instituto de Investigaciones Jurídicas de la UNAM

de ellos han sido previamente mencionados y analizados en este artículo. Así, es obvio que el sistema presidencialista, el constitucionalismo socialrevolucionario y la nacionalización de los recursos naturales han sido analizados extensamente y han influenciado sistemas jurídicos constitucionales de diferentes genealogías jurídicas.

La estructura federal que establece la Constitución de Querétaro es de hace un siglo y sus antecedentes constitucionales y políticos previos se articulan en dos niveles: constitucionalismo federal y constitucionalismo estatal. El anclaje constitucional del federalismo y la separación de poderes vertical o territorial hace comparable el federalismo mexicano al de los Estados Unidos de América. Además, el carácter federal concuerda claramente con el rol que las entidades subnacionales desplegaron tanto en el proceso revolucionario como en la historia moderna de México. Sin embargo, extraña que el federalismo mexicano no haya suscitado mayor interés en círculos comparativos. Entre los diferentes ámbitos a destacar podríamos resaltar el concepto de soberanía dual, que tanta polémica suscita en otros países descentralizados.

Esta falta de atención se debe básicamente a que tanto el federalismo como el constitucionalismo estatal no han desarrollado todo su potencial sino hasta hace bien poco:

a) Ambos conceptos fueron debilitados durante décadas por la lógica centralista del sistema de partido hegemónico (PRI) que existió hasta el año $2000 .{ }^{34} \mathrm{Si}$ bien durante ese periodo el constitucionalismo estatal (subnacional) estaba subordinado al constitucional nacional, con la llegada del sistema multipartidista y de competencia, las constituciones estatales han desarrollado un sistema de protección de derechos humanos. ${ }^{35}$

b) El federalismo también se ha visto menguado porque la Constitución es más "completa" o intervencionista que otras Constitucio-

34 Serna de la Garza, José María, "Strengthening State Constitutionalism from the Federal Constitution: the Case of Mexico", Perspectives on Federalism, vol. 6, núm. 2, 2014, pp. 74-88, disponible en: http://www.on-federalism.eu/index.php/jose-mariaserna-de-la-garza (consultada el 24 de agosto de 2016).

35 Ibidem. 
Esta revista forma parte del acervo de la Biblioteca Jurídica Virtual del Instituto de Investigaciones Jurídicas de la UNAM

nes federales, conteniendo aspectos que se reproducen en el sistema subnacional. ${ }^{36}$

El primero de los elementos destacados por Serna de la Garza viene a corroborar la trascendencia político-jurídica que tuvo la elección del presidente Vicente Fox en 2000; podríamos incluso hablar de efectos milenaristas o de fundación de una nueva era, como lo describen Zamora y Cossío en el sistema mexicano. ${ }^{37}$

Estos autores argumentan con razón que la alternancia provocó el fin del estilo presidencialista del PRI, aunque dicho cambio no fue acompañado por reformas constitucionales. ${ }^{38}$ Es decir, las atribuciones excesivas a favor del presidente del Ejecutivo se mantuvieron inalteradas en el texto constitucional.

El nuevo orden constitucional implicó una mayor separación de poderes (que no se había producido desde la aprobación del texto constitucional), un nuevo rol a la Corte Suprema (que pasó a ser un agente decisivo en el desarrollo de la ley y la sociedad) y cambios en el federalismo que hasta entonces se encontraban latentes. ${ }^{39}$

Otro elemento de interés que no ha suscitado la atención que parece merecer desde la disciplina del derecho constitucional comparado es la constitucionalización del ejército en México y el rol de las fuerzas armadas en la Constitución, sus atribuciones y límites.

En cuanto al acomodamiento constitucional de las fuerzas armadas y su rol preponderante en el proceso constituyente de 1917, como prueba bastaría una interpretación literal de la frase que inicia el texto constitucional y destaca el sujeto del que emana el Poder Constituyente, el C. Primer Jefe del Primer Ejército Constitucionalista, encargado del Poder Ejecutivo de la nación. Preponderancia militar que también se plasmó en los miembros del Congreso Constituyente, muchos de carrera militar y militares en ejercicio activo. A ello hay que añadirle el hecho de que fueron más militares quienes, desde afuera de las sesiones celebradas en el Teatro de la República de Querétaro, vigilaron y “tutelaron” los trabajos y discusiones de los con-

36 Serna de la Garza, José María, The Constitution of Mexico: a Contextual Approach, Oxford, Hart Publishing, 2013, pp. 11-13.

37 Zamora, Stephen y Cossío, José Ramón, “Mexican...”, cit., p. 412.

38 Idem.

39 Idem. 
Esta revista forma parte del acervo de la Biblioteca Jurídica Virtual del Instituto de Investigaciones Jurídicas de la UNAM

vencionistas constituyentes..$^{40}$ Una preponderancia militar que se corroboró con el gasto público dedicado a la partida de las fuerzas armadas entre 1920 y 1933, que alcanzó un total del $32 \%$ del dispendio público. ${ }^{41}$

El marco constitucional en relación con las fuerzas armadas gira básicamente en torno al artículo 13, que establece el fuero militar y que mantiene su redacción original cien años más tarde:

Subsiste el fuero de guerra para los delitos y faltas contra la disciplina militar; pero los tribunales militares en ningún caso y por ningún motivo podrán extender su jurisdicción sobre personas que no pertenezcan al Ejército. Cuando en un delito o falta del orden militar estuviese complicado un paisano, conocerá del caso la autoridad civil que corresponda.

La redacción y su inamovilidad en un siglo demuestran la validez de los límites que se impusieron a la jurisdicción castrense en el texto constitucional, con independencia del tutelaje militar del texto. Además, el artículo 129 de la Constitución enfatizaba este límite, al impedir en tiempo de paz cualquier función a la autoridad militar que no le fuesen las propias por la exacta conexión con la disciplina militar.

Estos artículos, sin embargo, generaron dudas razonables sobre el rol del ejército a la hora de afrontar algunos retos que ha tenido que afrontar el constitucionalismo mexicano en las últimas décadas; en especial, el combate contra el crimen organizado del narcotráfico o la respuesta armada a la insurgencia militar zapatista en Chiapas. Esta última acción justificó el uso de las fuerzas armadas con base en otro precepto constitucional: el artículo 89 fracción VI, reformado en 1944 y 2004 y que, entre las facultades y obligaciones del presidente, lo habilitaba a disponer de la totalidad de las fuerzas armadas para la seguridad interior y defensa exterior de la Federación.

En este sentido, el artículo 89 parece otorgar al presidente la potestad de disponer el ejército para implementar lo establecido en el artículo 29, sobre los casos de estado de excepción. Así, nos podríamos encontrar o bien ante una incongruencia en diferentes artículos constitucionales, o bien el artículo 13 puede interpretarse de manera laxa y desdibujando lo que parecía una línea roja clara establecida por el Constituyente hace un siglo.

40 Carbonell, Miguel, "El rol de las Fuerzas Armadas en la Constitución mexicana", Ius et Praxis, 8 (1), 35-51, 2002, p. 36.

41 Idem. 
Esta revista forma parte del acervo de la Biblioteca Jurídica Virtual del Instituto de Investigaciones Jurídicas de la UNAM

El artículo 29 de la Constitución bien podría ser modelo en otros Estados por el conjunto de garantías procedimentales y normativas que deben respetarse para la suspensión o restricción de derechos y libertades. Cabe destacar, desde un punto de vista comparativo, que sea la misma Constitución la que afirme que en caso de excepcionalidad (invasión, perturbación grave de la paz pública, o de cualquier otro que ponga a la sociedad en grave peligro o conflicto) podrán restringirse o suspenderse, en todo el país o en lugar determinado, el ejercicio de los derechos y las garantías que fuesen obstáculo para hacer frente, rápida y fácilmente a la situación; pero deberá hacerlo por un tiempo limitado, por medio de prevenciones generales y sin que la restricción o suspensión se contraiga a determinada persona.

Además, el Ejecutivo en caso de excepción no podrá restringir ni suspender, en ningún caso, el ejercicio de los derechos a la no discriminación, al reconocimiento de la personalidad jurídica, a la vida, la integridad personal, la protección de la familia, al nombre, a la nacionalidad; los derechos de la niñez; los derechos políticos; las libertades de pensamiento, conciencia y de profesar creencia religiosa alguna; el principio de legalidad y retroactividad; la prohibición de la pena de muerte; la prohibición de la esclavitud y la servidumbre; la prohibición de la desaparición forzada y la tortura; ni las garantías judiciales indispensables para la protección de tales derechos.

La restricción o suspensión del ejercicio de los derechos y garantías debe estar fundada y motivada en los términos establecidos por esta Constitución y ser proporcional al peligro a que se hace frente, observando en todo momento los principios de legalidad, racionalidad, proclamación, publicidad y no discriminación.

Una serie de garantías constitucionales explícitas que pueden considerarse como amplias si se comparan con los procedimientos establecidos en otros Estados en casos de emergencia y excepción, y que deberían servir como reflexión necesaria a operadores jurídicos en democracias constitucionales en un momento donde la excepcionalidad parece convertirse en norma en diferentes lugares del mundo.

\section{CONCLUSIÓN}

Una de las mayores críticas que se ha realizado a la Constitución mexicana es el carácter programático de muchos de sus principios y artículos. Espinoza nos afirma que: 
Esta revista forma parte del acervo de la Biblioteca Jurídica Virtual del Instituto de Investigaciones Jurídicas de la UNAM

Los derechos así fueron concebidos como declaraciones programáticas, apartándose del esquema tradicional de los derechos subjetivos y, por tanto, susceptibles de exigibilidad judicial. El régimen político ha sido trastocado, por lo que las condicionantes de la dominación han cambiado. ${ }^{42}$

El carácter programático o de aspiración de ciertos principios es práctica común cuando las autoridades constitucionales decisorias (Poder Constituyente y constituyente derivado) entienden sus funciones en términos de aspiraciones que quieren alcanzar. ${ }^{43}$ Es este carácter de aspiración constitucional lo que define un país, una nación en términos de futuro, sus objetivos y sus sueños. ${ }^{44}$ En el caso del constitucionalismo mexicano, el constitucionalismo social, la recuperación de la soberanía nacional y el hecho de forjar y asentar el concepto de identidad nacional fueron los sueños revolucionarios que los constituyentes de 1917 plasmaron en el texto.

Ciertamente, los derechos humanos, y entre ellos los sociales, cuestan dinero, como afirma Aharon Barak; sin embargo, este hecho no atenúa el mandato constitucional que impera sobre los poderes públicos. En México indudablemente se han producido políticas sociales como consecuencia del encaje constitucional de los derechos sociales y laborales.

Cossío aboga por la conversión de la Constitución en revolución y de la revolución en Constitución, considera que lo dispuesto en normas constitucionales no tenía importancia ni sentido entenderlas jurídicamente, lo relevante era identificar lo que fue determinante en el proceso revolucionario. ${ }^{45}$ Con esa intención se ha dedicado la primera parte de este artículo, si bien no siguiendo la recomendación de Cossío consistente en abandonar el análisis de la juridicidad constitucional y centrarse en el análisis no jurídico. ${ }^{46}$

Cossío nos invita, pues, a no celebrar nada; discrepo con su propuesta basada en un juicio sincrónico del autor sin destacar el significado que tuvo

42 Espinoza de los Monteros Sánchez, Javier, "Estado (social) y de derecho en México. Una óptica desde el garantismo jurídico-social", Revista Iberoamericana de Derecho Procesal Constitucional, núm. 9, pp. 61-83.

43 Scheppele, Kim Lane, "Aspirational and Aversive Constitutionalism: The Case of Studying Cross-Constitutional Influence Through Negative Models", International Journal of Constitutional Law I-CON, vol. 1, núm. 2, 2003, pp. 296-324.

44 Ibidem, p. 302.

45 Cossío, José Ramón, "Nada que celebrar", Nexos: Sociedad, Ciencia, Literatura, vol. 36, 434, 2014, p. 54.

46 Ibidem, p. 55. 
Esta revista forma parte del acervo de la Biblioteca Jurídica Virtual del Instituto de Investigaciones Jurídicas de la UNAM

la Constitución de Querétaro en 1917, lo avanzada que fue a su tiempo y los efectos globales que ésta tuvo. También es digno de celebrar la cantidad de principios y artículos que un siglo después siguen vivos y que han sido ejemplo en otros sistemas jurídicos.

También hay voces (Valadés, Fix-Fierro, Salazar, Covarrubias, Cárdenas, González Oropeza, Carbonell, entre otros) que por diferentes motivos abogan por un nuevo texto constitucional que sirva al país para afrontar desafíos que se le plantean en la actualidad, desde el constitucionalismo global, hasta la era digital y la globalización económica y política. Parte del argumento que justificaría una nueva Constitución es considerar la revolución como muerta. Si la revolución vive o no, la respuesta se encuentra en manos de los únicos capaces de contestar la cuestión, los mexicanos del siglo XXI, quienes en cualquier caso siempre podrán contar con su Constitución para seguir afrontando los nuevos retos que plantea el nuevo siglo, manteniendo el origen, los principios y los valores revolucionarios encarnados en su texto constitucional un siglo después.

\section{BIBLIOGRAFÍA}

ARENDT, Hannah, On Revolution, NuevaYork, Penguin Group, 2006.

BARAK, Aharon, "Unconstitutional Constitutional Amendments", Israel Law Review, núm. 44, 2011.

, Proportionality, Constitutional Rights and Their Limitations, Cambridge, Cambridge University Press, 2012.

Blasco IBÁÑEZ, Vicente, El militarismo mejicano, Valencia, Prometeo, 2006.

CARbonell, Miguel, "El rol de las Fuerzas Armadas en la Constitución Mexicana", Ius et Praxis, 8 (1), 35-51, 2002.

—_, "La xenofobia constitucionalizada", Biblioteca Jurídica Virtual del Instituto de Investigaciones Jurídicas de la UNAM, disponible en: http://historico.juridicas.unam.mx/publica/librev/rev/facdermx/ cont/246/art/art10.pdf.

CLINE, Howard F., "México: Versión madura de una revolución latinoamericana”, en STANLEY R., Ross (ed.), ¿Ha muerto la revolución mexicana?, México, La Red de Jonás, 1972. 
Esta revista forma parte del acervo de la Biblioteca Jurídica Virtual del Instituto de Investigaciones Jurídicas de la UNAM

Cossío, José Ramón, "Nada que celebrar”, Nexos: Sociedad, Ciencia, Literatura, vol. 36, 434, 2014.

ESPINOZA DE LOS MONTERos SÁNCHEZ, Javier, "Estado (social) y de derecho en México. Una óptica desde el garantismo jurídico-social”, Revista Iberoamericana de Derecho Procesal Constitucional, núm. 9.

Gerson, Pedro, "Consolidating the Mexican State: Constitutionalism during the Presidency of Plutarco Elías Calles", University of Pennsylvania, Scholary Commons, disponible en: http://repository.upenn.edu/cgi/ viewcontent.cgi? article $=1009 \&$ context $=$ hist_honors.

JACOBSHON, Gary Jeffrey, “An Unconstitutional Constitution”, International Constitutional Law Journal, ICON, vol. 4, núm. 3, 2006. Courts, 2014.

MADRID, Miguel de la, "La Constitución de 1917 y sus principios políticos fundamentales", Universidad de Colima, Instituto Universitario de Investigaciones Jurídicas", 2002.

MARTínez Hoyos, Francisco, Breve historia de la Revolución mexicana, Madrid, Nowtilus, 2015.

Molina EnRÍQueZ, Andrés, Los grandes problemas nacionales, México, ERA, 1909.

OLIVEIRA LOZANO, Guillermo, "La reforma al artículo 27 constitucional y la incorporación de las tierras ejidales al mercado legal de suelo urbano en México", Scripta Nova, 2005.

PARRA, Porfirio, "Estudio histórico-sociológico de la Reforma de México", La Gaceta de Guadalajara, Guadalajara, 1906.

SCHEPPELE, Kim Lane, "Aspirational and aversive constitutionalism: The case of studying cross-constitutional influence through negative models", International Journal of Constitutional Law I-CON, 2003, vol. 1 , núm. 2.

Serna de la Garza, José María, The Constitution of Mexico: a Contextual Approach, Oxford, Hart Publishing, 2013.

, "Strengthening state Constitutionalism from the Federal Constitution: the Case of Mexico", Perspectives on Federalism, vol. 6, núm. $2,2014$. 
Esta revista forma parte del acervo de la Biblioteca Jurídica Virtual del Instituto de Investigaciones Jurídicas de la UNAM

StAnley, R. Ross (ed.), ¿Ha muerto la revolución mexicana?, La red de Jonás, México, 1972.

TANNENBAuM, Frank, "La revolución agraria mexicana", Senderos. Los expedientes secretos, Universidad de México, 2002.

WeBER, Max, Ética protestante y espíritu del protestantismo, México, Colofón, 2011.

ZAMORA, Stephen y Cossío, José Ramón, "Mexican Constitutionalism after Presidencialismo", International Journal of Constitutional Law I-CON, vol. 4, núm. 2, 2006.

Páginas web

http://eleconomista.com.mx/sociedad/2015/12/12/mas-5-millones-visitan-virgen-guadalupe. 